\title{
The Microstructure Properties of Ni-W Alloy Electrodeposition
}

\author{
Mofeed A. Jaleel \\ Applied Science Dep., University of Technology, \\ Baghdad, IRAQ \\ Mofeed04@yahoo.com \\ Received: 11-June-2017
}

http://doi.org/10.29194/NJES21010082

\author{
Eilaf Z. Gurji \\ Applied Science Dep., University of Technology, \\ Baghdad, IRAQ \\ Fulla.zaki@yahoo.com
}

Revised: 12-Nov.-2017 Accepted: 18-Dec.-2017

\begin{abstract}
The Electrodeposition process has been used to prepare Nickel-Tungsten alloys on low carbon steel substrate by using ammonical citrate bath. The influence of deposition condition by variation of current density $\left(0.04-0.2 \mathrm{~A} / \mathrm{cm}^{2}\right)$ and solution temperature $\left(60-70{ }^{\circ} \mathrm{C}\right)$, on the microstructure was studied. The optical microscope and the scanning electron microscopy (SEM) were used to study the morphology of the deposit while the energy dispersive spectroscopy (EDS) was used to approximate the composition, in addition to X-Ray diffraction examination. The results show that the current efficiency has the major influence on the tungsten content in the alloys due to the formation of ternary complex which reflected into the properties of the deposit.
\end{abstract}

Keywords: Ni-W alloy, Tungsten content, current efficiency.

\section{Introduction}

The term "Induced codeposition" was coined by Brenner to describe the situation in which a metal that cannot be electroplated alone from aqueous solution is codeposited in the presence of another metal, forming an alloy [1]. It is widely known that Tungsten cannot be electrodeposited from an aqueous solution of sodium tungstate or any other soluble compound containing this element. Nevertheless, it is quite easy to deposit $\mathrm{Ni}-\mathrm{W}$ alloys, if a suitable nickel compound, such as nickel sulfate, is added [2].

All the researcher in the related work attempted to understand the mechanism of deposition of Ni-W alloys, taking into account the distribution of different ions with the concentration of citrate and ammonia. Citrate forms a complex with the nickel ion as follows:

$$
N i^{2+}+x \mathrm{Cit}^{3-} \rightarrow(\mathrm{Ni})(\mathrm{Cit})_{x}^{2-3 x}
$$

Citrate forms a complex also with the tungstate ion as following,

$\mathrm{WO}_{4}^{2-}+\mathrm{Cit}^{3-}+x \mathrm{H}^{+} \rightarrow\left[\left(\mathrm{WO}_{4}\right)(\mathrm{Cit})(\mathrm{H})_{x}\right]^{x-5}$ (2).

The ternary complex of $\mathrm{Ni}, \mathrm{W}$ and citrate can be formed,

$$
\begin{gathered}
{[(\mathrm{Ni})(\mathrm{Cit})]^{-}+\left[\left(\mathrm{WO}_{4}\right)(\mathrm{Cit})(\mathrm{H})\right]^{4-} \rightarrow} \\
{\left[(\mathrm{Ni})\left(\mathrm{WO}_{4}\right)(\mathrm{Cit})(\mathrm{H})\right]^{2-}+\mathrm{Cit}^{3-}}
\end{gathered}
$$

Then the deposition of Ni-W alloy can be achieved through ternary complex formation.

$$
\begin{aligned}
& {\left[(\mathrm{Ni})\left(\mathrm{WO}_{4}\right)(\mathrm{Cit})(\mathrm{H})\right]^{2-}+8 e^{-}+3 \mathrm{H}_{2} \mathrm{O} \rightarrow} \\
& \mathrm{NiW}+7(\mathrm{OH})^{-}+\mathrm{Cit}^{3-}
\end{aligned}
$$

In this system the deposition of nickel alone and Ni-W alloy take place.

Ammonia concentration has also a substantial influence on the composition of the alloy deposit, since ammonia competes with citrate as a ligand for the nickel ions, the increase in ammonia concentration reduce the tungsten content in the deposit. [3][4]

\section{Experimental}

Nickel-Tungsten alloys were electrodeposit from aqueous solution containing: nickel sulfate, sodium tungstate as a source of nickel and tungsten respectively, sodium citrate as a complexing agents, ammonium chloride as a complexing agents and to improve the faradic efficiency. The concentration of $\mathrm{Ni}-\mathrm{W}$ alloys bath constituents showing in table (1). The $\mathrm{pH}$ was

\begin{tabular}{|c|c|}
\hline Materials & Concentration \\
\hline $\begin{array}{l}\text { Nickel Sulfate } \\
\left(\mathrm{NiSO}_{4} \cdot 6 \mathrm{H}_{2} \mathrm{O}\right)\end{array}$ & $0.65 \mathrm{M}$ \\
\hline $\begin{array}{l}\text { Sodium Tungstate } \\
\left(\mathrm{Na}_{2} \mathrm{WO}_{4} \cdot 2 \mathrm{H}_{2} \mathrm{O}\right)\end{array}$ & $0.145 \mathrm{M}$ \\
\hline $\begin{array}{c}\text { Sodium Citrate } \\
\left(\mathrm{Na}_{3} \mathrm{C}_{6} \mathrm{O}_{7} \mathrm{H}_{5} \cdot 2 \mathrm{H}_{2} \mathrm{O}\right)\end{array}$ & $0.5 \mathrm{M}$ \\
\hline $\begin{array}{l}\text { Ammonium Chloride } \\
\left(\mathrm{NH}_{4} \mathrm{Cl}\right)\end{array}$ & $0.5 \mathrm{M}$ \\
\hline
\end{tabular}
measured by using digital $\mathrm{pH}$ meter and adjusted to a value of $(8.0 \pm 0.2)$ through addition of $\mathrm{H}_{2} \mathrm{SO}_{4}$ and $\mathrm{NaOH}$.

Table (1): The Ni-W alloy bath concentration

A sheet of low carbon steel with dimensions $(5 \times 5) \mathrm{cm}$ with thickness $2 \mathrm{~mm}$ was used as cathode. Deposition was conducted at current density $(0.04,0.08,0.12,0.16$ and 0.2$) \mathrm{A} / \mathrm{cm}^{2}$ and Temperature $(60,70){ }^{\circ} \mathrm{C}$. The anode-to-cathode surface area ratio was approximately $5 \mathrm{~cm}$ as showing in Fig (1). the structure of the deposits was analyzed by X-ray diffraction (XRD) while the morphology of the deposits was observed by scanning electron microscopy (SEM) and optical microscope $(\mathrm{OM})$ in addition to energy dispersive 
spectroscopy (EDS) to determine the approximate composition of the alloy.

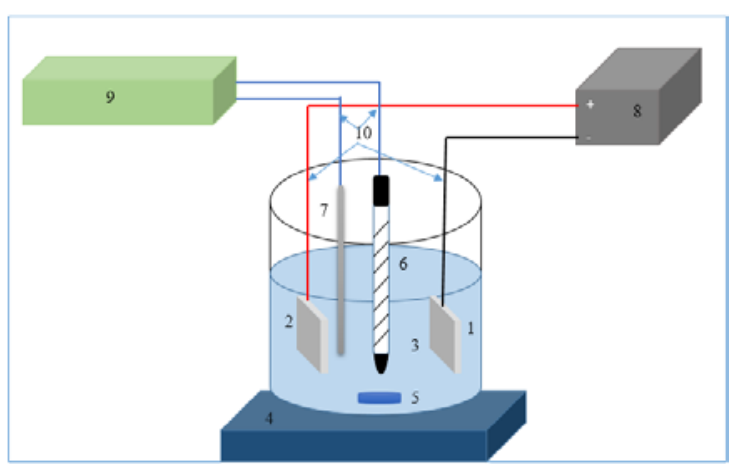

Figure (1): Sketch of electrodeposition bath design; (1) cathode, (2) anode, (3) bath solution, (4) magnetic stirrer, (5) magnetic bar, (6) heater, (7) thermocouple, (8) power supply, (9)heat controller, (10) connecting wires.

\section{Results and Discussion}

The calculation of tungsten content with nickel in the deposited alloy were done by EDS examination. The effect of current density on the tungsten content at different bath temperatures showing in Fig (2).

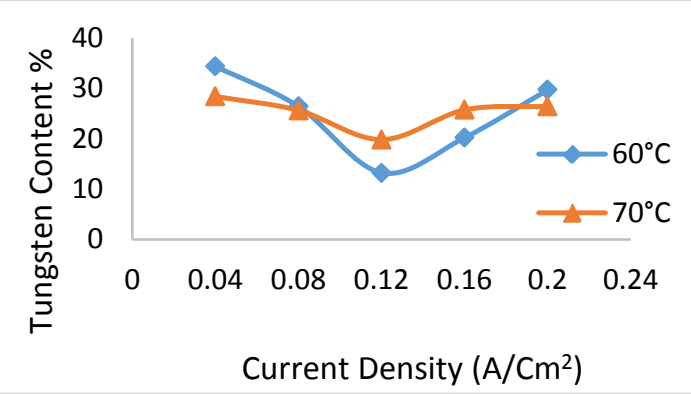

Figure (2): The effect of current density on tungsten content in the alloys.

While figure (3) shows the current efficiency changes with current density at different bath temperatures.

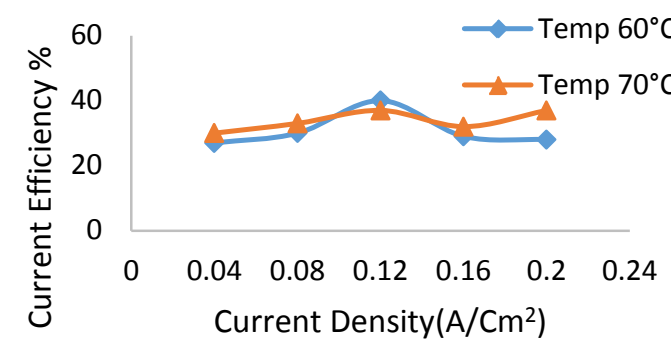

Figure (3): The relation of current efficiency and current density in the solution.

From the figures above noticed that the tungsten content in the deposited was affected by current efficiency, at low current density range the tungsten content was decreased with current density increased, in the intermediate point of current density the lowest value of tungsten content for two temperatures and at high current density range the tungsten content increased by increasing the current density that return to the influence of current efficiency with current density, the difference in the current efficiency is due to the formation of ternary complex of $\mathrm{Ni}, \mathrm{W}$ and citrate. [5] [6]

The optical microscope shows the microcraks of the deposited surface, the tungsten content effect on the microcraks concentration, that is high tungsten content (at low current density range) was associated with high microcracks concentration compared with low tungsten content in the intermediate point of current density, while at high current density range the microcracks concentration increased again due to the increasing of tungsten content and that clarified in Fig (4), (5).

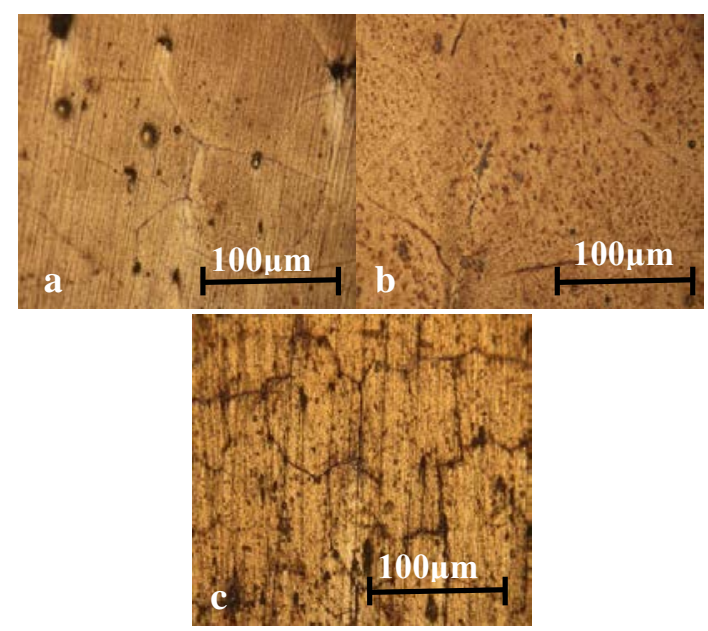

Figure (4): The morphology of $\mathrm{Ni}-\mathrm{W}$ at bath temperature $70^{\circ} \mathrm{C}$ with different current density; (a) 0.04, (b) 0.12and (c) $0.2 \mathrm{~A} / \mathrm{cm}^{2}$

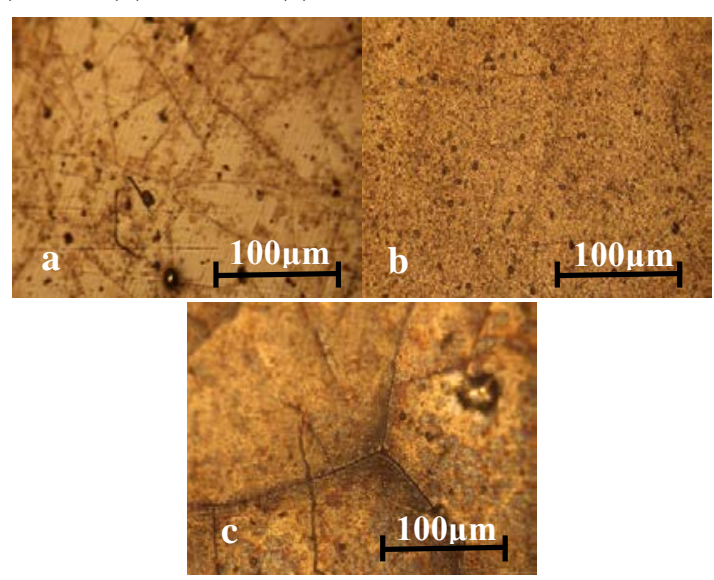

Figure (5): The morphology of $\mathrm{Ni}-\mathrm{W}$ at bath temperature $60^{\circ} \mathrm{C}$ with different current density; (a) 0.04 , (b) 0.12 and (c) $0.2 \mathrm{~A} / \mathrm{cm}^{2}$

While the microcracks depth was affected with current density that at high current density the microcrack depth is increased. The best 
surface morphology was achieved with $(\mathrm{J}=0.04$ $\mathrm{A} / \mathrm{cm}^{2}$ ), while the microcracks depth (size) increased with increasing the current density due to the increasing of (1) Hydrogen evolution during electrodeposition. (2) Residual stress.

The grain size of the deposited alloy was estimated by scanning electron microscope (SEM), as shown in figures (6),(7) for different bath temperature.
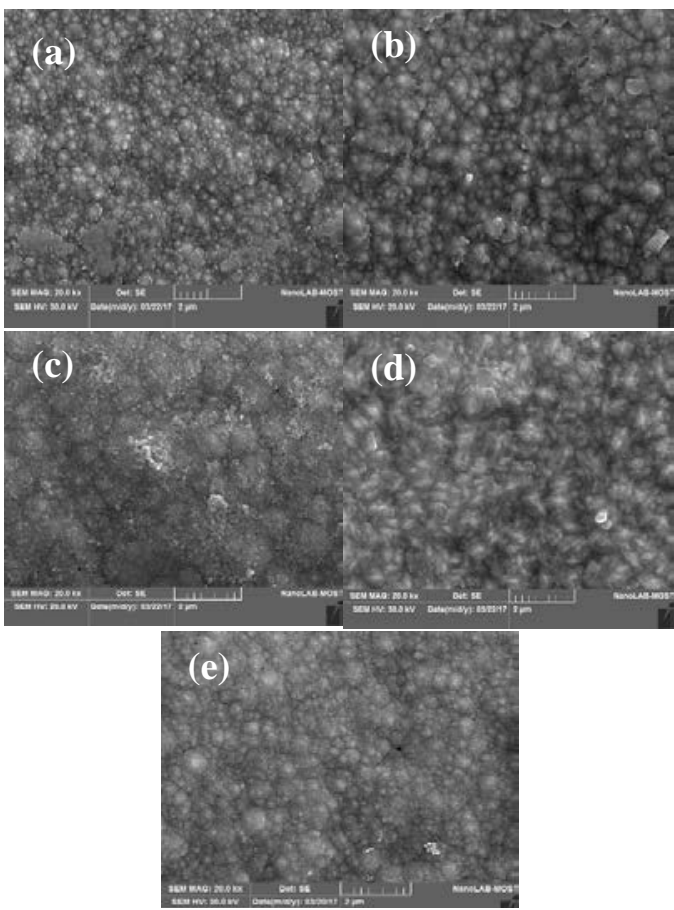

Figure (6): SEM micrographs showing the grain size of Ni-W alloy with bath temperature $60^{\circ} \mathrm{C}$, at different current densities : (a) 0.04, (b) 0.08 (c) 0.12 , (d) 0.16 and (e) $0.2 \mathrm{~A} / \mathrm{cm}^{2}$.

The grain size of the deposited alloy was affected by tungsten content in the deposit as showing in figures (6 and 7), deposited alloys with high tungsten content had small grain size and vice versa in the case of deposited alloys with low tungsten content. The surface coating exhibits a cauliflower like structure as a result of the presence of nodules, the size of nodules increased and decreased corresponding with tungsten content.

Also the current density had a little influence on the grain size that at low current density the grain growth rates was low and that caused emergence of small grain size.

The structure of Ni-W alloys was investigated by XRD. The diffractograms of $\mathrm{Ni}-\mathrm{W}$ alloys shows five picks with small broad. As shown in figure (8). Four of the picks at $2 \theta$ angle of $\approx 44^{\circ}$, $\approx 51^{\circ}, \approx 75^{\circ}$ and $\approx 91^{\circ}$ are with correspond to the (f.c.c) phase of $\mathrm{W}$ solid solution in nickel.[7] while the first peak of the XRD pattern at $2 \theta$ angle of $\approx 41.4^{\circ}$ correspond to $\mathrm{NiWO}_{4}$.[8]
The crystalline size of Ni-W alloys was calculated using Scherrer's equation ${ }^{\text {[7]: }}$

$$
D=\frac{0.9 \lambda}{B \cos \theta}
$$

The result that calculated shown in table (2). The presence of tungsten reduces the crystal size, at high tungsten content the crystal size found the lower value and that clearly shows in figure (9).

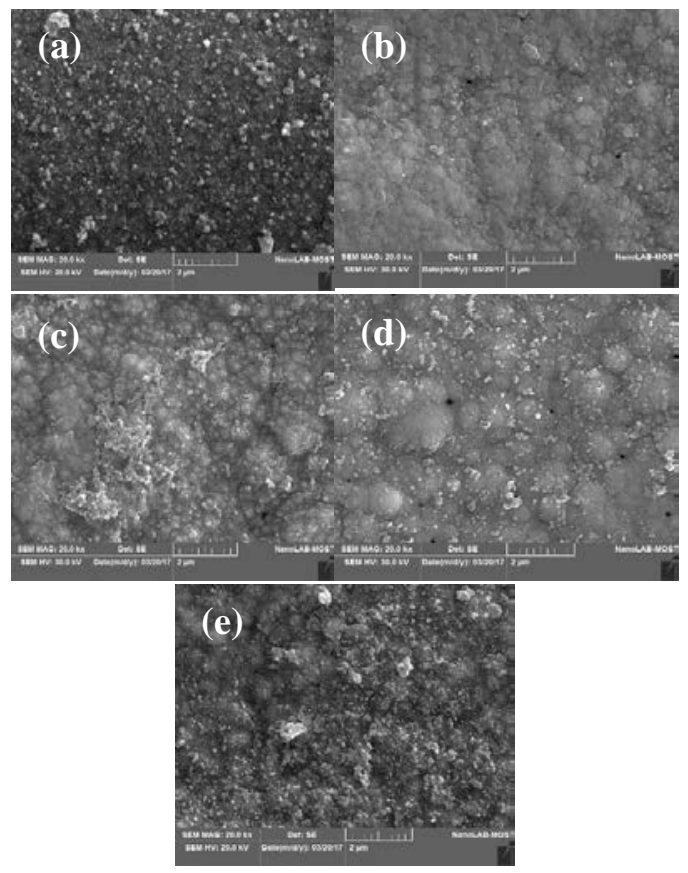

Figure (7): SEM micrograph showing the grain size of Ni-W alloy with bath temperature $70^{\circ} \mathrm{C}$, at different current densities: (a) 0.04, (b) 0.08, (c) 0.12, (d) 0.16 and (e) $0.2 \mathrm{~A} / \mathrm{cm}^{2}$.

Table (2): Information calculated from XRD

\begin{tabular}{|c|c|c|c|c|}
\hline $\begin{array}{c}\mathrm{J} \\
\mathrm{A} / \mathrm{cm}^{2}\end{array}$ & $\begin{array}{c}\text { Tem } \\
\mathrm{p} \\
\left({ }^{\circ} \mathrm{C}\right)\end{array}$ & $2 \theta(\mathrm{deg})$ & $\begin{array}{c}\text { FWHM } \\
(\mathrm{deg})\end{array}$ & $\begin{array}{c}\text { Crystalli } \\
\text { ne size } \\
(\mathrm{nm})\end{array}$ \\
\hline 0.12 & 60 & 43.8145 & 0.94960 & 9.024 \\
\hline 0.04 & 70 & 43.7183 & 1.05900 & 8.075 \\
\hline 0.12 & 70 & 41.4011 & 0.89780 & 9.464 \\
\hline 0.2 & 70 & 43.8465 & 1.14220 & 7.510 \\
\hline
\end{tabular}

\section{Conclusion}

Based on the experimental results presented in this work, it is possible to draw the following conclusions:

1. The sample with current density 0.04 $\mathrm{Amp} / \mathrm{cm}^{2}$ and $60^{\circ} \mathrm{C}$ bath temperature was the best according to tungsten content.

2. The tungsten content can be controlled by controlling deposition parameters to be suitable for certain application.

3. The high current density reflects on the deposited structure by forming high crack concentration with high crack depth and width. 
4. The crystals size of the deposited is effected by the tungsten content.

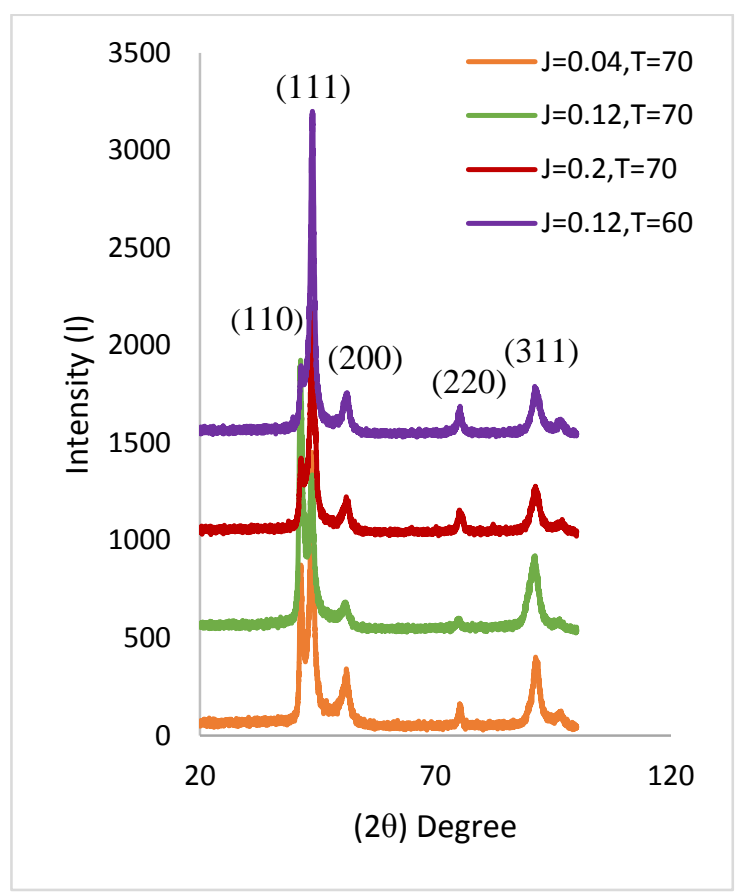

Figure (8): XRD pattern of Ni-W alloy deposited at different current densities and temperature.

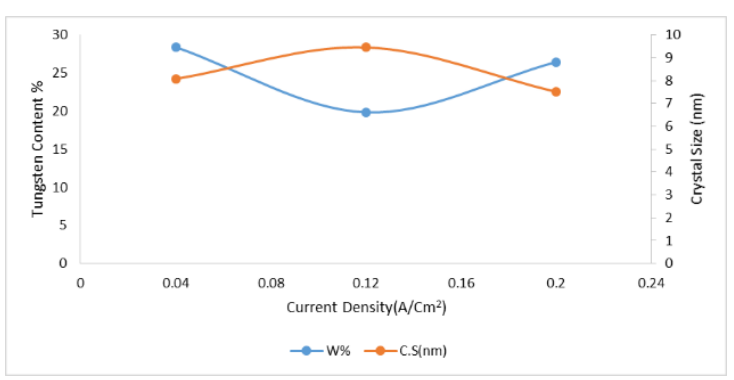

\section{References}

[1] Younes, O., and E. Gileadi. "Electroplating of $\mathrm{Ni} / \mathrm{W}$ alloys I. Ammoniacal citrate baths." Journal of The Electrochemical Society 149.2 (2002): C100-C111.

[2] Takigawa, Yorinobu, et al. "Application of electroforming process to bulk amorphous Ni-W alloy." Materials transactions 52.1 (2011): pp.3740.

[3] Mizushima, Io. Electrodeposition of $\mathrm{Ni}-\mathrm{W}$ Alloy and Characterization of Microstructure and Properties of the Deposits. Diss. PhD Thesis, 2006.

[4] Younes, O., and E. Gileadi. "Electroplating of high tungsten content Ni/W alloys" Electrochemical and Solid-State Letters 3.12 (2000): 543-545.

[5] Eliaz, N., T. M. Sridhar, and E. Gileadi. "Synthesis and characterization of nickel tungsten alloys by electrodeposition" Electrochimica Acta 50.14 (2005): pp.2893-2904.

[6] Eliaz, Noam, and Eliezer Gileadi. "Induced codeposition of alloys of tungsten, molybdenum and rhenium with transition metals." Modern aspects of electrochemistry. Springer New York, 2008. 191-301.

[7] Wu, Yiyong, et al. "Ni-W alloy electrodeposition from a bath containing an organic amine substitute for inorganic ammonia." Plating and surface finishing 90.2 (2003): 46-49.

[8] ] Juškènas, R., I. Valsiūnas, V. Pakštas, and R. Giraitis. "On the state of $\mathrm{W}$ in electrodeposited Ni-W alloys." Electrochimica Acta 54, no. 9 (2009): 2616-2620.

Figure (9): The relation between the tungsten content and the crystal size.

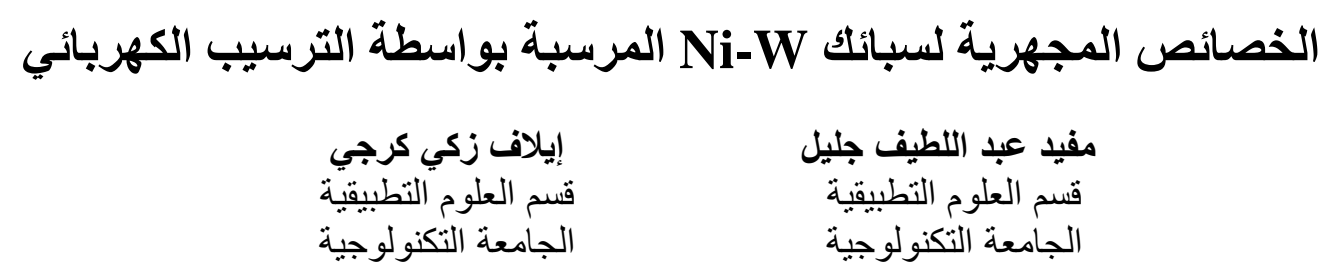

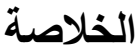

أستخدمت طريقة الترسيب الكهربائي لتحضير سبائك من النيكل- تنغسنن على قاعدة من الحديد واطئ الكاربون بأستخدام أحو اض تحتوي على الأمونيا و الستر آيت. حيث تم دراسة تأثثر متغير ات عملية الطلاء من حيث كثافة التيار

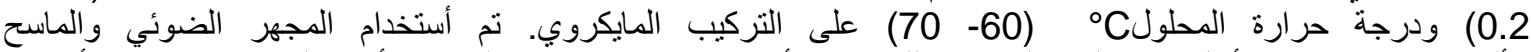

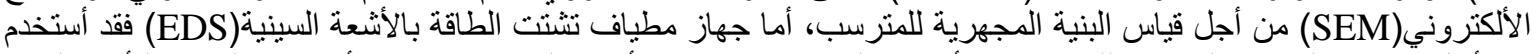

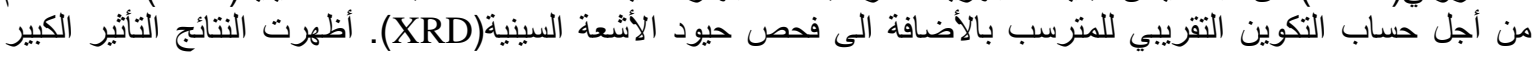

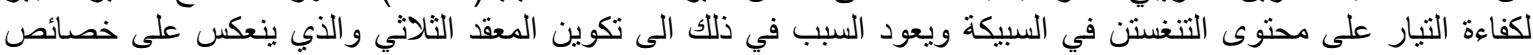

